\title{
The Significance of Information Visualisation Based On the Symbolic Semantics of Peking Opera Painted Faces (POPF)
}

\author{
Ding Wang ${ }^{1}$, Dr Jinsheng Kang ${ }^{1}$, Dr Shengfeng Qin ${ }^{2}$ \\ ${ }^{1}$ School of Engineering and Design, ${ }^{2}$ Department of Design \\ ${ }^{1}$ Brunel University, ${ }^{2}$ Northumbria University \\ ${ }^{1}$ Uxbridge, Middlesex, UB8 3PH, UK, ${ }^{2}$ Newcastle upon Tyne, Tyne and Wear, NE1 8ST, UK \\ 1ing.Wang@,brunel.ac.uk, Jinsheng.Kang@brunel.ac.uk
}

\begin{abstract}
Peking Opera as a branch of Chinese traditional cultures and arts has a very distinct colourful facial makeup for all actors in the stage performance. Such make-up is stylised in typical cultural elements which all combined together to form the painted faces to describe and symbolise the background and characteristic of specific roles. The Peking Opera Painted Faces (POPF) was taken as an example to study the information visualisation and transmission, to see how information and meanings can be effectively expressed through the colourful visual elements. In order to identify the state-of-the-art in the related Culture Inspired Design as one of the design principles, the literature resources including illustrations of POPF were investigated, and also the semantic features and elements of other similar forms of modern design which has close connection with multiple aspects of social life. The study has proved that the visual elements of POPF played the most effective role in the information transmittion. Future application of this culture resource may include product design, interaction design, system design and service design around the world.
\end{abstract}

Keywords-Cultural-based product design; information visualization; Peking Opera Painted Faces; semantics; transmission.

\section{INTRODUCTION}

The research considers current Peking Opera Painted Faces (POPF) as a culture resource. The research aims to prove the information visualisation is the most effective approach to the information transmission in modern society. Owing to the basis of the origin and development of POPF and the radical feature of information transmission are basically the same, that is to express the most important information to people as needed only in the shortest time possible. Thus this research is to combine both sides together. The first research objective is to study and summarise the visualised symbolic semantics of POPF and its design methods. The second research objective is to investigate how the visualized information can be transmitted in the existing ways and/or in a maximum possible way.

\section{A. Peking Opera Painted Faces (POPF)}

The term "painted face" refers to the colourful facial make-up of an actor in traditional Peking Opera (Fig. 1).
Such make-up is worn mostly by actors playing roles known as Jing (painted faces) and Chou (clowns). It is stylised in form, colour, and pattern to symbolise the characteristics of specific roles [1]. Therefore, a knowledgeable audience, seeing a painted face, can tell easily whether it is a hero or a villain, a wise man or a fool, to be loved or hated, respected or ridiculed. Thus the painted face is quite appropriately called 'a mirror of the soul'. Painted faces were not created by the fancy of some individual. They are the creations of generations of dramatic artists, based on their observations and life experience and their analysis of the dramatis personae. Surely, the POPF is characterised by symbolism and exaggeration.

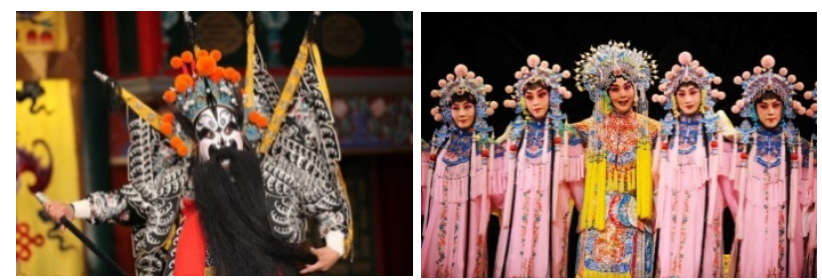

Figure 1. Peking Opera (Beijing Opera).

As Peking Opera developed, vividly painted faces enable audiences to see expressions clearly even from a distance, a great advantage in the days when dramatic performances were usually staged in the open air before large crowds. As a result, actors apply powder, ink, paint, and soot to their faces, creating the art of POPF (Fig. 2).
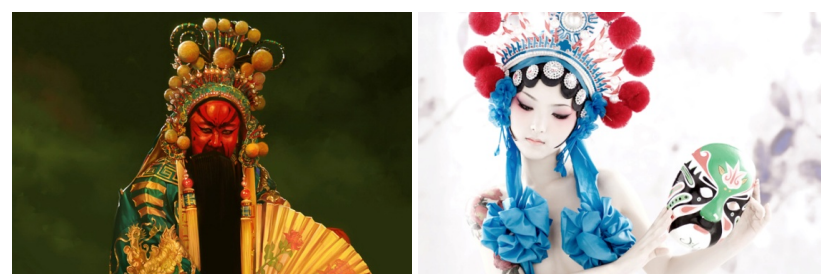

Figure 2. Peking Opera Painted Faces (POPF).

POPF as a branch of traditional Chinese cultures and arts has been known all over the world. However, modern young people do not truly understand that it is not only a painted accessorize for the performance art, it is also created by design principles and methods. 


\section{B. Information Visualization}

\section{1) Information Design and Visual Design}

People make contact with information all the time. Information design is used to help people grasp the information details in the shortest time and understand visual materials. Dirk Knemeyer thought that information design is an integrated vessel that collects other subjects so as to create an excellent information scheme. The famous information design expert, American Nathan Shedroff, separated design as information design, mutual design, and conscious design; he thought information design is to devise the message that the producers want to express, mutual design is made as the response of the customers, and conscious design needed to be planned from appreciation of the beauty and feeling psychology [2].

Human feeling is combined with senses of vision, hearing, smelling, tasting and touching. According to the results of scientific research, $70 \%$ of the messages come from the sense of vision. So, academic circles are focused mainly on visual design, which is aimed at human visual senses. Thus, both visual and philosophical information are considered as the cultural access point [3].

Cross-cultural research on visual design is very active, but there is no unified and specific definition. Design of visual information is produced by visual medium for people to pass on messages, and the design of information is at its center, with visual perception design as its soul, and mutual design as its essence. A study has shown that culture-centred design of interface demonstrated very positive feedbacks from users [4]. Cultural patterns have significant influences on the product design conceptualization [5].

\section{2) Language, Image and Meaning}

A scholar, named Wang Bi made comparatively clear analysis of the dialectical relationship among "language", "image" and "meaning", which developed the theories upheld by Zhuang $\mathrm{Zi}$, whose opinion is "The use of the image aims to have the meaning fully manifested, and the use of language aims to have the image explicitly pictured. It is the most effective way to convey the meaning though displaying the image, so does weave up the image through linguistic forms. This is because: 'meaning' fully comes out with the help of 'image', and 'image' vividly occurs with the help of 'language' [6].

Although language certainly acts as the actual choice to note all these strange thoughts, it is hard to be used to re-picture them ingeniously. Thus, there must be such transferring processes: thought-image-language, that is, the well-conceived image will perfect the effective language to convey the thoughts.

\section{METHODOLOGY}

It is necessary to get close contact with information visualisation in terms of symbolic semantics of POPF. Therefore, this research is starting from the related works and primary researches in order to identify the state-of- the-art in the culture inspired design in terms of design methods and processes. POPF is used as a focus point to guide the study.

\section{A. Literatue Review}

For the literature review, an investigation of documental resources searching was explored with a series of keywords which are related to information visualization or cultural transforming design at the beginning. Then it was to classified words with similar meanings or characteristics. After that, it was designed search set-ups with the combination of keywords from different classifications.

\section{B. Interview}

For the interview, a face-to-face talk with a director of Jingju (Peking Opera) Theater Company of Beijing was conducted to fully understand the history of Peking Opera in its different periods of development and unique features of Peking Opera compared with multiple performance arts around the world. On top of this, some inspiration about the design in the future to spread Chinese traditional culture was received through this interview.

\section{Data Collection}

In order to identify existing applications without documental resources, a series of historical remains and products with commemorative meanings related to POPF for making a summary of the whole classifications of different applied methods with the using of cultural elements was explored. Besides, a semantics database of cultural elements of POPF from among its facial colours and characters, types and symbolic meanings was partially completed, which was sourced from certain typical and well-known illustrations of POPF.

\section{Case Study}

Since the research of existing products of POPF, POPF can be applied by the using of 3D image, 3D image with multi-elements. Besides, there are a lot of forms of arts already applied its transferring information to product design. Through the observation the results, it is proved that feature elements of POPF can be transferred and mapped into product design, because the feature itself provides widespread cultural connotation.

\section{FINDINGS \& RESULTS}

The cultural and creative industry is a newly emerging industry globally developed from various cultures. It is also a kind of aesthetic economy and a creative industry [7]. Culture is a kind of code hidden in these product designs or in the producers. Design is de-code, representation, or de-culture [8]. Thus through the transformation to interpretation of the current cultural styles and characteristics, and through the meanings of codes, signs, and representation, the relation among design, culture, and code is an integrated one.

The basic colours in modern POPF are red, black, white, etc. Originally, colours were used just to emphasize or exaggerate a person's natural complexion. Despite 
POPF's riot of colours and strong decorative value, they are only a dozen types of painted faces. Types of POPF are based on the physical and mental characteristics of dramatis personae. For both practical and aesthetic purposes, POPF must deliberately exaggerate or distort the most typical features while omitting less important details (Table. 1-3).

Connections between Information Visualization and POPF:
TABLE I. Symbolic SEMANTICS OF POPF

\begin{tabular}{|c|l|l|}
\hline $\begin{array}{c}\text { Cultural } \\
\text { Elements }\end{array}$ & \multicolumn{1}{|c|}{$\begin{array}{c}\text { Description } \\
\text { (In Brief) }\end{array}$} & \multicolumn{1}{c|}{ Meaning Languages } \\
\hline $\begin{array}{c}\text { Facial } \\
\text { Colours }\end{array}$ & Black, red, white & $\begin{array}{l}\text { Colours are used to emphasize or } \\
\text { exaggerate a person's natural } \\
\text { complexion. }\end{array}$ \\
\hline Types & $\begin{array}{l}\text { Full face, } \\
\text { Three-tile face, } \\
\text { Cross face }\end{array}$ & $\begin{array}{l}\text { Types are based on the physical } \\
\text { and mental characteristics of } \\
\text { dramatics personae. }\end{array}$ \\
\hline $\begin{array}{l}\text { Symbolic } \\
\text { Meanings }\end{array}$ & $\begin{array}{l}\text { Patterns with } \\
\text { strong decorative } \\
\text { value }\end{array}$ & $\begin{array}{l}\text { Deliberately exaggerate or distort } \\
\text { the most typical features while } \\
\text { omitting less important details. }\end{array}$ \\
\hline
\end{tabular}

TABLE II. ANALYSIS OF CULTURAL ElEMENTS (TyPiCAL ILluSTRATIONS OF POPF)

\begin{tabular}{|c|c|c|c|c|}
\hline \multirow[b]{2}{*}{ Illustration } & \multirow[b]{2}{*}{ Figure } & \multicolumn{3}{|c|}{ Cultural Elements } \\
\hline & & $\begin{array}{c}\text { Facial colour V.S. the } \\
\text { characteristics of specific role }\end{array}$ & $\begin{array}{c}\text { Type of the } \\
\text { painted face }\end{array}$ & Symbolic meanings \\
\hline & $\begin{array}{l}\text { Dou Erdun } \\
\text { in } \\
\text { Stealing the } \\
\text { Imperial } \\
\text { Steed }\end{array}$ & Blue: valor and resolution & $\begin{array}{l}\text { Three-tile face: } \\
\text { (The flowered } \\
\text { Three-tile face) } \\
\text { A bold warrior } \\
\text { or a green-wood } \\
\text { hero }\end{array}$ & $\begin{array}{l}\text { Two halberds: Wrinkles } \\
\text { Yintang (The gall-shaped figure): Prowess } \\
\text { Weapon pattern: The deadly two-hook weapon }\end{array}$ \\
\hline & $\begin{array}{l}\text { Bao Zheng } \\
\text { in } \\
\text { The Un- } \\
\text { grateful } \\
\text { Husband }\end{array}$ & $\begin{array}{l}\text { Black: of loyalty and } \\
\text { integrity }\end{array}$ & Black full face & $\begin{array}{l}\text { The white knitted brows: } \\
\text { loyalty to country and concern for the welfare of the people } \\
\text { / underscoring the judge's ironclad integrity and strict } \\
\text { observance of the law } \\
\text { The white crescent: } \\
\text { the mysterious powers possessed by this judge, who tries in } \\
\text { the upper world by day and in the netherworld at night [9]. }\end{array}$ \\
\hline
\end{tabular}

TABLE III. ANALysis of Symbolic MEANings (Typical PATterns)

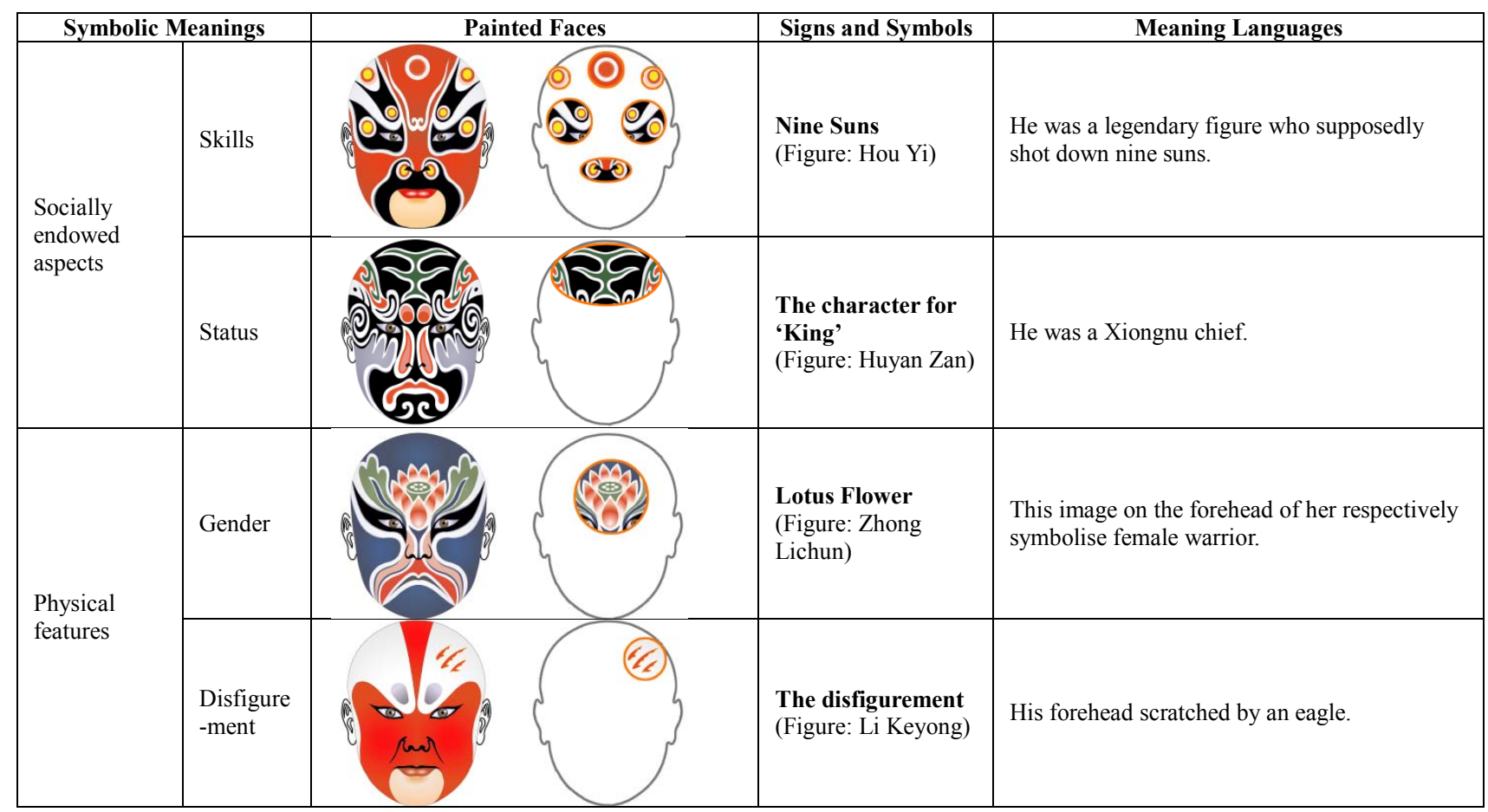

The analysis of symbolic semantics of POPF is a procedure of deconstructing and decoding the POPF. Among the procedure, a complete illustration of POPF can be split into a plurality of combinational part, which is a process from the surface to the point. A painted face represents a role of character, while its various components represent various characteristics of this character, for example: general character, specific background status, a special experience, a certain physical feature, even a certain associated object with the character. After the refined analysis, the POPF has become particularly vivid, and it provides all the information that need to be known by audience during performances. Besides, this way of information transmittion is the most intuitive and fastest. 

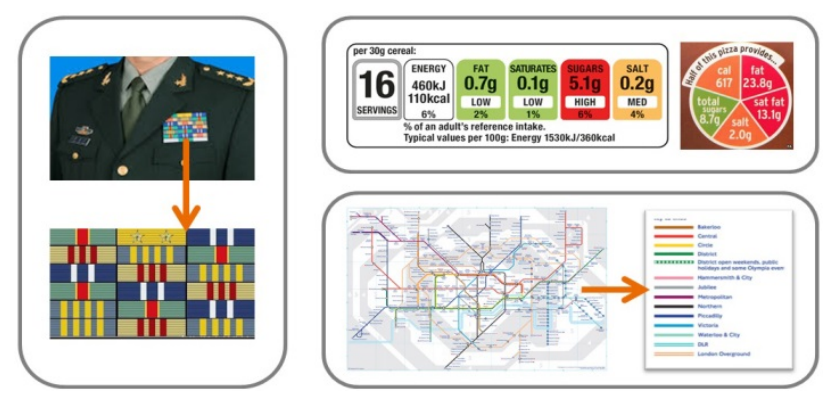

Figure 3. Similar Information Visualised Method on non-Peking Opera theme.

Colour does not only embody the national culture, but also is an important factor on product design [10]. Similarly, in people's lives there is no lack of other similar examples of information transmittion. For example the decoration of military uniform on the left breast, it is to convey the type of armed services, the belonged designation of a military unit, even personal information such as blood type through colors and shapes. It is not only to quickly identify the basic identity of soldier, more importantly, also to provide the most rapid staffing and medical help in the war with special needs. Another example is the food labels, it is to convey ingredients and nutritional composition through colors and numbers and ratios which is aim to simplify lengthy text description by means of tables, pie charts and bar charts, etc. Its role is to allow people to choose the effective and right food according to their needs or special restrictions or conditions. Besides, a further example of the London Underground map, which is to convey the information of different lines and stations by colors and shapes. Color represents line; it is not only to be appeared on the map, also to be painted on the vehicle body with using the corresponding color. Meanwhile the dot and the ring represent deeper meanings of station, such as transit station, station with disabled access, overlapped train station, etc (Fig. 3).

POPF is a visual form of information transmittion in the Peking Opera; while other non-Peking-Opera-themed illustration is using other visual forms. Thus, the effectiveness of visualisation reflected out with the comparison with other ways of information transmittion. Visual communication is the most intuitive, and spread the most correct information to people. Once a visual signal is widely known, its effect is much greater than a character signal. Because the readability of text depends on people's level of education and the capacity of understanding, but the current widely used visual signal just expressed by simple colors and shapes, and it is easily understandable.

\section{DISCUSSION}

Existing design methods of information visualization are summarized into two categories:

Based on the symbolic semantics of POPF, compared with the research gap and the research aim, the connection between them was established and design principles and transforming methods among similar painted arts and cultures with using similar symbolic expression ways to POPF was found. The most popularity of current transforming methods is "Side-effect transforming" like deforming part of patterns, changing colours, adding textures with the using of body tattoo and stage performances.

Besides, the most of current existing products simply used the traditional meanings of POPF or mapped the entire illustrations of POPF, fewer amounts of products was designed with transforming methods through setting up the connections between the component parts of the painted face and the function of the products.

Generally, sharply contrasting colours were used in the POPF. Besides, eyes, ears, nose, mouth and facial contours were delineated clearly; and a character's most distinctive features, such as thick brows, large eyes, upturned nose or wide mouth, were usually exaggerated.

Design Principles (General):

- To reflect Age: the height and curvature of the fishtail lines (crow's feet).

- To express Temperament: the fluctuation of the nasolabial folds (the curves flanking the mouth pit).

- To symbolise Person's Character: the pattern of the yintang line (A strip shaped like a gallbladder extending from the top of the nose ridge to the top of the forehead).

Although these symbolic meanings of facial colour are fairly well established, they are not hard and fast. Great flexibility is allowed in the use of colour. Moreover, through borrowing and interchanging details many subtypes have been created.

To sum up, the design method is that an optimistic person is usually portrayed with clear eyes and smooth brows, while a grief-stricken or cruel person has halfclosed eyes and wrinkled brows. With the addition of appropriate signs and symbols, a painted face can reveal not only physical and physiological features, but also socially endowed aspects and even the articles or weapons a character habitually uses.

In order to match the technological level of modern industrial production, design should explored some more profound meanings beneath the colourful and artistic outer skin in terms of POPF or other types of art, that is cultural meaning. Thus the conception of the semantic database of POPF was born. It contains the whole semantics of POPF, even a small pattern could be interpreted by its semantics. After that, semantics which are dissociated from complete painted faces can be applied by designers. The systematical semantics might be exclusively used. That will be using the complete expressions to correspond with another information system as a toolkit, or recombine semantics within the system, and then the reorganised information forms new semantics which could be used directly, or as a toolkit again to guide designers. 


\section{CONCLUSION \& FUTURE WORK}

Throughout the basic necessities of human beings, nothing can leave without visual communication. For example, the designs based on Peking-Opera-themed are including conceptual design, information design, system design and computer game design, etc. However, a few plenty of products are the re-design of applications starting from the truly deeper semantics of POPF (Table. 4). In fact, most of current brands have one or several distinctive logo or image. Then sometimes people choose to remember their icons, rather than their names; because a distinctive icon can be accurately kept in the mind. Therefore, new application of POPF would be a really good and functional design.

TABLE IV. INFORMATION VISUALISED METHOD ON PEKING OPERA THEME

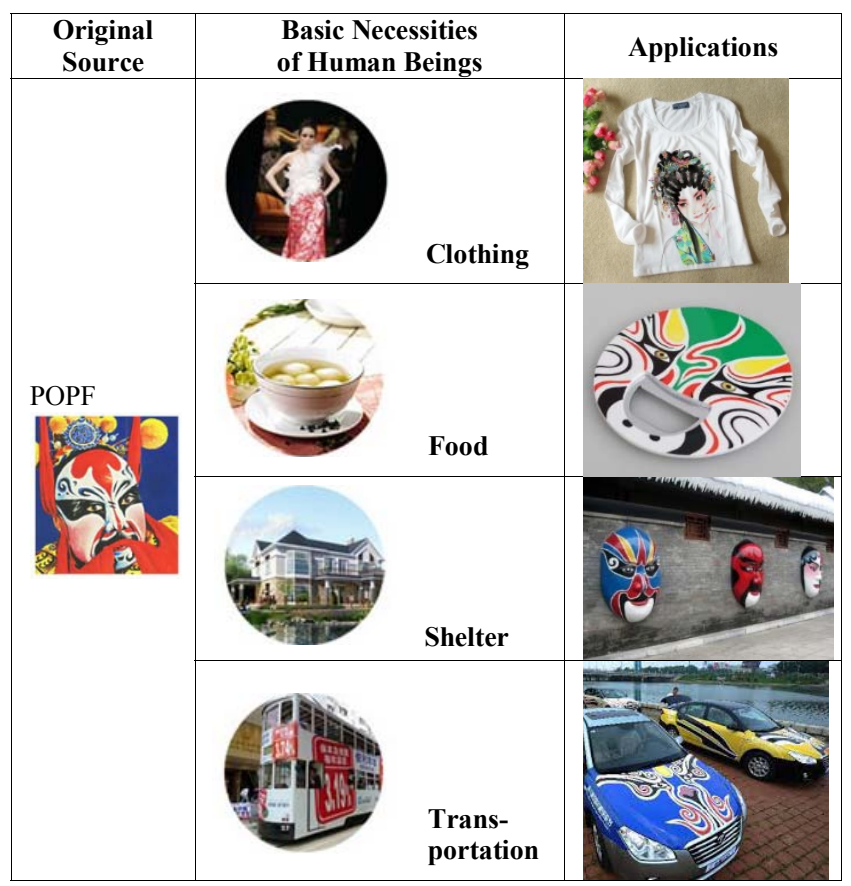

- Continue to summarise the database of Symbolic Semantics of POPF from among its cultural elements, and generate the database as a digital system.

- Apply the database to cultural-based product design - the modern expression of traditional design semantics and the innovate comprehension of original Painted Faces.

- Explore the method of transmitting higher level information associated with indicated visualisation for cultural-based product design.

Application of such a culture resource may include product design, interaction design, system design and information design in China and Western countries, along with the integration of other elements of traditional Chinese cultures and arts.

The current work of this study is to establish a database of proving the information visualized method between painted faces and meaning languages. Furthermore it is to add personal design thinking to the original languages and semantic meanings of POPF, to make the expression meanings of painted faces completely corresponding to the indicated information of a specific designing product one by one. The semantics of the POPF and the corresponding product must be understood and accepted by people according to their needs, and it cannot be mismatched.

\section{REFERENCES}

[1] M. Zhao, Peking Opera Painted Faces, 2nd ed., Beijing: Morning Glory Publishers, 1997.

[2] L. Ouyang, R. Jiang, "The analysis and research of visual perception and image processing in visual information design - take google earth for example," IEEE: Image Analysis and Signal Processing (IASP), [Digests 2011 International Conference on Image Analysis and Signal Processing, Hubei, pp. 336-339, 2011].

[3] B. D. Leong, H. Clark, "Culture-based knowledge towards new design thinking and practice - A dialogue," Massachusetts Institute of Technology, Design Issues, vol. 19, 2003, pp. 48-58.

[4] S. Shen, M. Woolley, S. Prior, "Towards culture-centred design," Interacting with Computers, vol. 18, pp. 820-852, 2006.

[5] M. Razzaghi, M. Ramirez, R. Zehner, "Cultural patterns in product design ideas: comparisons between Australian and Iranian student concepts," Design Studies, vol. 30, pp. 438-461, 2009.

[6] Z. Li, X. Zhang, G. Kang, "A comparative study of literary images between Chinese and English from the cognitive perspective," CCSE: Asian Social Science, No. 8, vol. 4, August 2008.

[7] R. Lin, M. Sun, Y. Chang, Y. Chan, Y. Hsieh, Y. Huang, "Designing 'culture' into modern product: A case study of cultural product design," Lecture Notes in Computer Science, vol. 4559. [Digests 2nd International Conference on Usability and Internationalization, UI-HCII 2007, Beijing, China]. January 2007, pp. 146-153.

[8] C. Chen, B. Chen, C. Jan, "A study of innovation design on Taiwan culture creative product - A case study of the facial mask of Ba Ja Jang," Lecture Notes in Computer Science, vol. 5623. [Digests 3rd International Conference, IDGD 2009, San Diego, CA, USA, pp. 337-346, 2009].

[9] X. Fu, Peking Opera Painted Faces, Tianjing: Baihua Literature And Art Publishing House, August 2009.

[10] Y. Zhou, L. Yang, "An attempt of using the national color culture on product design," Applied Mechanics and Materials, vol. 37-38. Switzerland: Trans Tech Publications, 2010, pp. 94-97. 